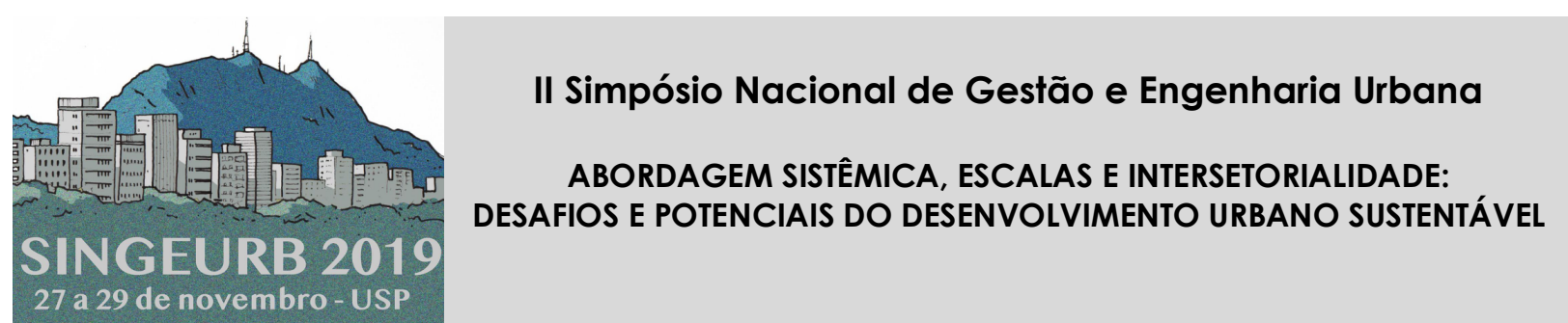

\title{
Evolução do déficit habitacional no Brasil pós-20001
}

\section{Evolution of housing deficit in Brazil after 2000}

\author{
Cardoso, Luiz Reynaldo Azevedo' \\ ' Departamento de Engenharia de Construção Civil - Escola Politécnica - \\ Universidade de São Paulo - luiz.cardoso@poli.usp.br
}

\begin{abstract}
RESUMO
Este artigo apresenta um fragmento de uma pesquisa mais ampla, realizada pelo autor para Tese de Livre-Docência, cujo objetivo é analisar alguns aspectos da evolução da política habitacional no Brasil, relacionados à organização institucional, financiamento, produção e qualidade da produção, entre outros. Neste artigo é apresentada uma síntese da análise de um dos aspectos relacionados à produção habitacional, que é a evolução do déficit habitacional no período pós -2000. São apresentados os conceitos de déficit utilizados e os resultados da evolução do mesmo, ocorrida no período, elaborados pelo autor, baseando-se em dados da Fundação João Pinheiro (FJP). Conclui-se que houve uma redução do déficit no período, importante historicamente por ter sido a primeira vez em que isso ocorreu no país, mas quantitativamente reduzida. São discutidas as principais causas da redução do déficit e da magnitude dessa redução, comparando os resultados obtidos com os de outros autores.
\end{abstract}

Palavras-chave: Déficit habitacional, Política habitacional.

\begin{abstract}
This article presents a fragment of a broader research carried out by the author for Thesis of Associate Professor, whose objective is to analyze some aspects of the evolution of housing policy in Brazil, related to institutional organization, financing, production and quality of production, among others. This article presents a synthesis of the analysis of one of the aspects related to housing production, which is the evolution of the housing deficit in the post -2000 period. The concepts of deficit used and the results of the evolution occurred in the period, prepared by the author, based on data from the João Pinheiro Foundation (FJP), are presented. It is concluded that there was a reduction of the deficit in the period, important historically because it was the first time this has happened in the country, but quantitatively reduced. The main causes of deficit reduction and the magnitude of this reduction are discussed, comparing the results obtained with those of other authors.
\end{abstract}

Keywords: Housing deficit, Housing policy.

\section{INTRODUÇÃO}

O atendimento das necessidades habitacionais brasileiras tem se mostrado um enorme desafio. Mesmo com todos os esforços realizados e a importante evolução ocorrida nas

\footnotetext{
${ }^{1}$ CARDOSO, Luiz Reynaldo. Evolução do déficit habitacional no Brasil pós-2000. In: II SIMPÓSIO NACIONAL DE GESTÃo E ENGENHARIA URBANA: SINGEURB, 2019, São Paulo. Anais... Porto Alegre: ANTAC, 2019.
} 
últimas décadas, convivemos ainda com grandes necessidades de produção e melhorias habitacionais. Diante de um problema de tal magnitude faz-se necessária a constante avaliação das políticas habitacionais implementadas e a análise de seus resultados.

Este artigo apresenta um fragmento de uma pesquisa mais ampla, realizada pelo autor, cujo objetivo é analisar alguns aspectos da evolução da política habitacional no Brasil, relacionados à organização institucional, financiamento, produção e qualidade da produção, entre outros.

Neste artigo é apresentada uma síntese da análise de um dos aspectos relacionados à produção habitacional, que é a evolução do déficit habitacional no período pós-2000.

\section{DÉFICIT HABITACIONAL}

O conceito de déficit utilizado é o desenvolvido pela Fundação João Pinheiro, em trabalho pioneiro realizado em 1995, com reformulações posteriores da própria FJP e contribuições de outros autores, especialmente Cardoso e Araújo (2009). O déficit habitacional compõe as necessidades habitacionais juntamente com outra duas categorias: inadequação e demanda demográfica.

Déficit habitacional é a necessidade de construção de novas habitações, pela deficiência e escassez de moradias no estoque existente, num determinado momento. A deficiência é a necessidade de reposição do estoque, devido à precariedade e desgaste da sua estrutura física. A escassez é a necessidade de incremento do estoque, devido à coabitação familiar, famílias que vivem em cômodos (cortiços), uso de imóveis destinados a fins não residenciais, e o gasto excessivo com aluguel.

A inadequação de moradia refere-se às necessidades decorrentes de atendimentos específicos, sem a necessidade de construção de novas moradias, mas sim de melhorias. É definido pela carência ou inadequação de infraestrutura; adensamento excessivo (densidade excessiva de moradores por dormitório), inadequação fundiária e inexistência de unidade sanitária domiciliar exclusiva.

A demanda demográfica é o incremento ao estoque para atender ao crescimento demográfico, sem levar em consideração o déficit e a inadequação.

Os conceitos foram acoplados às definições utilizadas nos censos do Instituto Brasileiro de Geografia e Estatística (IBGE) e pesquisas nacionais por amostra de domicílios (PNAD's), de modo a se ter os dados que possibilitassem o cálculo das necessidades habitacionais.

Há possibilidade de uma moradia ser considerada inadequada por mais de um componente. Portanto, os componentes de inadequação não podem ser somados. Os subtipos de inadequação não podem ser somados ao déficit, uma vez que este corresponde exclusivamente à necessidade de construção de novas moradias. No presente artigo é analisada a evolução do déficit conforme esta definição.

\section{EVOLUÇÃO DO DÉFICIT HABITACIONAL}

É apresentada a seguir a evolução do déficit (absoluto e relativo) com base nos dados da FJP, entre 2000 e 2014, conforme FJP (2005, 2013, 2015 e 2016) para os anos em que os mesmos são disponíveis. 
Gráfico 1 - Evolução do déficit habitacional, absoluto e relativo

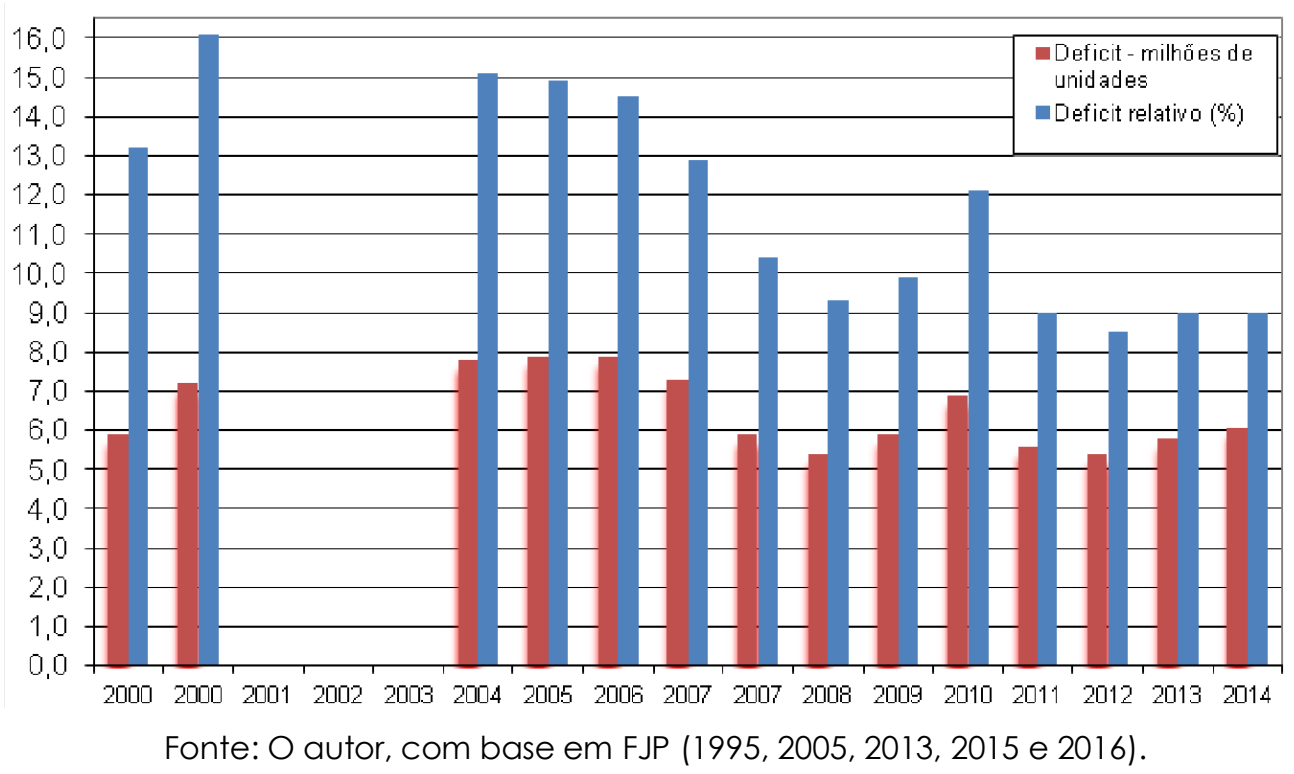

Nota explicativa: em 2000, houve mudança de metodologia, sendo que o maior número incorpora depreciação e ônus excessivo com aluguel. Em 2007 houve nova mudança de metodologia, que fez reduzir significativamente a quantificação do déficit, referente às famílias conviventes. Passou a ser considerado déficit somente as que declaram que desejam morar fora, sendo que antes todas eram consideradas. Foi excluído também do déficit a depreciação e foi incluído cortiço como déficit.

Os anos de 2000 e 2010 utilizam bases de dados comparáveis, pois são baseadas em censos, mas houve modificação na metodologia entre estes dois anos. Essa mudança ocorreu em 2007 e por isso há dois resultados para este ano (um conforme a metodologia anterior e o outro conforme a nova), e explica também a redução observada entre 2007 e os anos anteriores, conforme nota explicativa ao gráfico 1.

A partir de 2007, excluindo-se 2010, as comparações são consistentes, pois a metodologia e base de dados é a mesma. Observa-se no Gráfico 1 que o déficit diminuiv entre 2007 e 2008, aumentou entre 2008 e 2009, possivelmente devido à crise dos subprimes em 2008 e o arrefecimento do boom imobiliário que ocorria. O déficit voltou a cair entre 2009, 2011 e 2012, que coincide com o lançamento e implementação do Programa Minha Casa Minha Vida (PMCMV). A partir de 2013 e 2014 passou a subir, não significativamente. Portanto, a evolução parece coerente com a situação geral da economia e do setor.

Entre 2007 e 2012, período em que houve queda mais longa e acentuada do déficit, a redução foi de aproximadamente 5,9 milhões para 5,4 milhões (aproximadamente 8\%), enquanto que o déficit relativo caiu de $12,9 \%$ para $8,5 \%$ (aproximadamente $34 \%$ ). No período 2007-2014 houve aumento de aproximadamente $3 \%$ no déficit absoluto, sendo que para 0 relativo houve redução de aproximadamente $13 \%$.

Assim, é possível concluir que houve redução entre 2007 e 2012 e é possível que tenha havido redução também entre 2000 e 2007, embora não conclusiva devido às diferentes bases de dados. Portanto, para o período pós - 2000 até 2014 é possível concluir que provavelmente houve redução. A redução do déficit absoluto, se de fato ocorreu, foi relativamente pequena, inferior a 5\% e houve, com mais certeza, redução no déficit relativo.

\section{DISCUSSÃO E ANÁLISE}

A explicação para a redução do déficit é o grande esforço de priorização da questão habitacional no período, representado por várias medidas governamentais no âmbito federal, tendo como marco principal inicial a criação do Ministério das Cidades em 2003. Foram implementadas a partir de então diversas ações visando o aumento do financiamento 
e do estímulo à produção habitacional, e o aumento da produção subsidiada para população de baixa renda, medidas estas que não serão analisadas neste artigo. Cita-se como exemplo mais representativo desses esforços o PMCMV, que contratou 4,4 milhões de unidades habitacionais até 2016, tendo sido entregues até o mesmo ano aproximadamente 3,0 milhões (AMORE et al, 2015). Esses números fazem do PMCMV o maior programa habitacional do país nos últimos 30 anos, próximo da produção do extinto BNH, até então a maior existente historicamente. O BNH financiou 4,3 milhões de moradias, mas em 22 anos de existência (1964 e 1986). Se considerado o período pós - 2000 anterior ao PMCMV - 2002 a 2009 - a produção supera a do período BNH. (MARICATO, 2011).

Devem ser considerados também fatores ocorridos antes do período analisado, que propiciaram ambiente favorável ao aumento do crédito e da produção habitacional. Destaca-se a estabilização econômica, a criação de legislação de regulação do financiamento imobiliário, entre outros, que não serão também abordados neste artigo.

Essas conclusões também são confirmadas por outros autores. Lima Neto, Furtado e Krause (2013), que usam a mesma metodologia da FJP, concluem que o déficit diminuiu sistematicamente entre 2007 e 2012, passando de 5,59 milhões em 2007 para 5,24 milhões em 2012 (aproximadamente 5\%). Esta redução ocorreu ao mesmo tempo em que houve incremento do número total de domicílios. De outro lado, segundo o mesmo estudo, a evolução do déficit por faixa de renda mostrou que na de até 3 Salários Mínimos (SM), o déficit aumentou aproximadamente $4 \%$ (passou de 70,7 para $73,6 \%$ ). Nas faixas mais altas o déficit caiu ( $11,5 \%$ entre 3 e 5 SM, $10 \%$ entre 5 e 10\%, e 30\% na acima de 10 SM). Portanto, embora o déficit tenha caído, persistiu a concentração do mesmo na faixa de menor renda.

Ferro (2013) relaciona a redução do déficit habitacional com o aumento de crédito na economia. Citando dados da FJP, mostra que o déficit reduziv entre 2000 e 2008 (5,9 para 5,5 milhões - aproximadamente $7 \%$ ). Mostra também que reduziu o número de pessoas por domicílio (3,76 para 3,31) entre 2000 e 2010, assim como o número de moradores por dormitório (2,10 para 1,75 no mesmo período).

Rolnik e Nakano (2009) apontam que, graças ao aumento de crédito ocorrido a partir de 2005 ocorreu pela primeira vez na história uma diminuição do déficit habitacional. Entretanto, essa diminuição não ocorreu para as classes de menor renda, pois apenas $10 \%$ aproximadamente das unidades ofertadas foram para a faixa de 0 a $3 \mathrm{SM}$, que corresponde a aproximadamente $90 \%$ do déficit habitacional, enquanto $50 \%$ aproximadamente foram para renda maior que 5 SM.

\section{CONCLUSÕES}

Houve redução no déficit habitacional no período pós - 2000, o que pode ser considerado um resultado histórico, por ter sido a primeira vez em que isto ocorreu no país. Entretanto, a redução é quantitativamente pequena, principalmente face ao grande esforço feito nessa área, traduzido em grande aumento do financiamento e da produção no período. A explicação para isto é o aumento da produção não ter sido direcionado majoritariamente aos extratos de renda mais baixos, que correspondem a mais de $90 \%$ do déficit.

Conclui-se pela enorme dificuldade e desafio que é atender os extratos sociais que devem ser o foco das políticas habitacionais, o que exige forte aumento da produção subsidiada.

Essa constatação fica ainda mais agravada com a crise instalada após 2014/2015, que certamente causou retrocesso na evolução até então ocorrida, com consequências ainda não avaliadas. 


\section{REFERÊNCIAS}

AMORE, C. S., SHIMBO, L. Z., RUFINO, M. B. C. (org.). Minha casa...e a cidade? Avaliação do programa minha casa minha vida em seis estados brasileiros. Rio de Janeiro, Letra Capital, 2015.

CARDOSO, A. L.; ARAÚJO, R. L. Necessidades Habitacionais no Brasil. In: Açōes Integradas de Urbanização de Assentamentos precários. 1a. ed. BRASÍLIA : MINISTÉRIO DAS CIDADES/ALIANÇA DE CIDADES, 2009.

FERRO, L. P. M. Crédito e formação de domicílio no Brasil. Dissertação (Mestrado). Faculdade Economia, Administração e Contabilidade, Universidade de São Pulo, 2013.

FUNDAÇÃO JOÃO PINHEIRO (FJP). Déficit habitacional no Brasil. Belo Horizonte, FJP, 2005.

FUNDAÇÃO JOÃO PINHEIRO (FJP). Déficit habitacional municipal no Brasil. Belo Horizonte, FJP, 2013.

FUNDAÇÃO JOÃO PINHEIRO (FJP). Déficit habitacional no Brasil 2011-2012. Belo Horizonte, FJP, 2015.

FUNDAÇÃO JOÃO PINHEIRO (FJP). Déficit habitacional no Brasil 2013-2014. Belo Horizonte, FJP, 2016.

LIMA NETO, V. C. ; FURTADO, B. A. , KRAUSE, C. Estimativas do déficit habitacional brasileiro (PNAD 2007-2012). Instituto de Pesquisa Econômica Aplicada (IPEA). Brasília, IPEA, 2013.

MARICATO. E. O impasse da política urbana no Brasil. Petrópolis, RJ, Vozes, 2011.

ROLNIK, R.; NAKANO, K. As armadilhas do pacote habitacional. Le Monde diplomatique Brasil. Edição 20, Março 5, 2009. Disponível em <https://diplomatique.org.br/as-armadilhasdo-pacote-habitacional/>. Acesso em 13/09/2016. 